\title{
Metabolic biomarkers for predicting cardiovascular disease
}

\author{
This article was published in the following Dove Press journal: \\ Vascular Health and Risk Management \\ 25 January 2013 \\ Number of times this article has been viewed
}

\author{
Jana E Montgomery ${ }^{1,2}$ \\ Jeremiah R Brown ${ }^{1-3}$ \\ 'Dartmouth-Hitchcock Medical \\ Center, Division of Cardiology, \\ Lebanon, NH, USA; ${ }^{2}$ Geisel School \\ of Medicine, Hanover, NH, USA; \\ ${ }^{3}$ The Dartmouth Institute for Health \\ Policy and Clinical Practice, Lebanon, \\ $\mathrm{NH}$, USA
}

\begin{abstract}
Cardiac and peripheral vascular biomarkers are increasingly becoming targets of both research and clinical practice. As of 2008, cardiovascular-related medical care accounts for greater than $20 \%$ of all the economic costs of illness in the United States. In the age of burgeoning financial pressures on the entire health care system, never has it been more important to try to understand who is at risk for cardiovascular disease in order to prevent new events. In this paper, we will discuss the cost of cardiovascular disease to society, clarify the definition of and need for biomarkers, offer an example of a current biomarker, namely high-sensitivity C-reactive protein, and finally examine the approval process for utilizing these in clinical practice.
\end{abstract}

Keywords: cardiac biomarkers, cardiovascular disease

\section{Cost of cardiovascular disease to society}

Overall, an estimated 83 million people in the United States have cardiovascular disease (defined as heart disease and stroke), which equates to nearly 1 in 3 adults. A 40-yearold male in the United States has a nearly $50 \%$ chance of developing coronary disease and a similar aged woman a $32 \%$ chance in her lifetime. ${ }^{1,2}$ Sadly, the rates are much higher for many minority groups including African-Americans, Native Americans, Native Hawaiians, and Hispanics. While risk-factor modification, particularly smoking cessation and hypertension treatment, has decreased the severity of cardiovascular disease and improved medical care and technologies have decreased the overall death rate since the 1960s and 1970s, the aging of the population stands to cause a sudden increase in these numbers as the so-called "Baby Boomer" generation reaches their $60 \mathrm{~s}$ and 70s. Heart disease is the leading cause of death in the United States. Cardiovascular disease led to 812,000 deaths, nearly half of which 405,000 were from heart disease in 2008 , the last year for which data is available. ${ }^{3}$

Cardiovascular-related medical care accounts for greater than $20 \%$ of all the economic costs of illness in the United States as of 2008, which is equivalent to \$298 billion dollars. ${ }^{3}$ Figure 1 illustrates how great a problem cardiovascular disease is, particularly compared to any other cause of medical expenditures. The total cost is not just a number, but rather it represents a large percentage of emergency room visits, office visits, and hospitalizations.

Hippocrates is quoted as saying that it is more important to know what sort of person has a disease than to know what sort of disease a person has. On an individual level, it is helpful to diagnose each person with his or her diseases; however, for the benefit of the public's health, it is necessary to find ways to identify groups of people
Correspondence: Jana E Montgomery Dartmouth-Hitchcock Medical Center, Department of Cardiology, One Medical Center Drive, Lebanon, NH 03756, USA $\mathrm{Tel}+\mathrm{I} 6036503539$

Fax +l 6036533576

Email jana.e.montgomery@hitchcock.org 


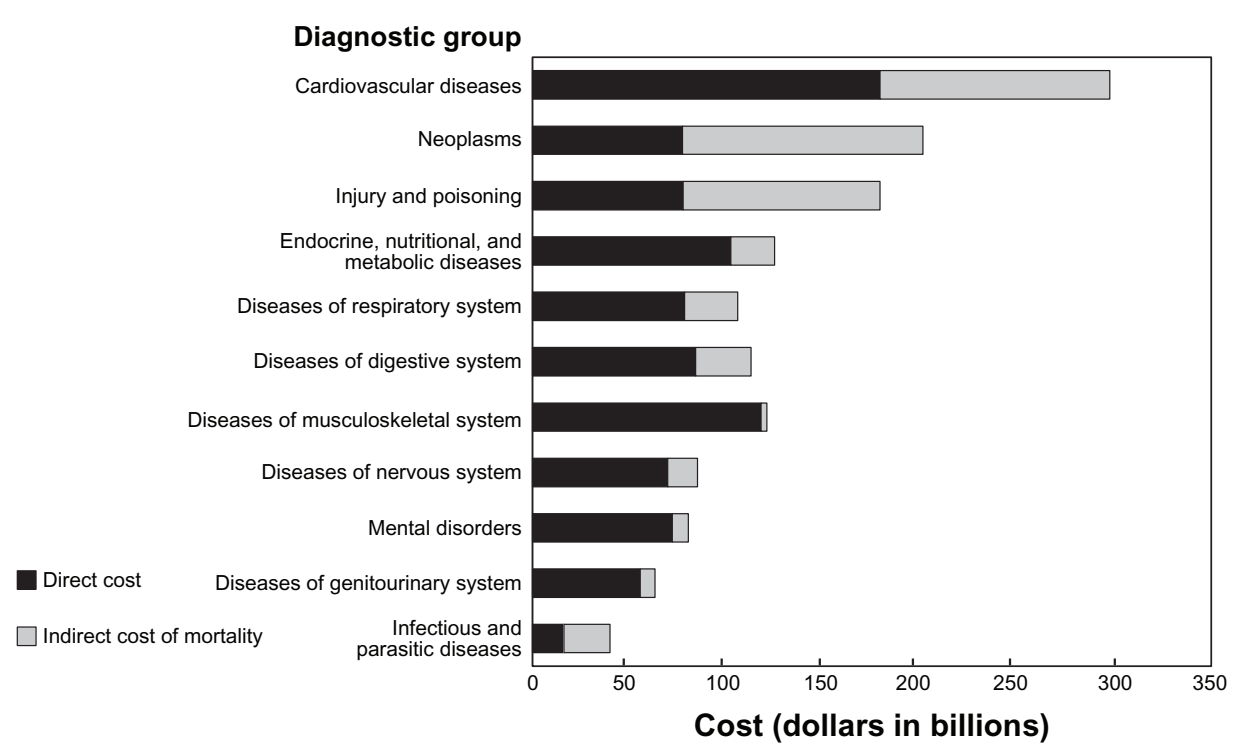

Figure I Total economic cost of the leading diagnostic groups in the US, $2008 .{ }^{61}$

Copyright @ 201I. Reproduced with permission from the National Heart, Lung, and Blood Institute; National Institutes of Health; US Department of Health and Human Services. Available from: http://www.nhlbi.nih.gov/about/factbook/FactBook20I I.pdf.

who may be at risk and attempt to mitigate those risks either before an event happens or prior to its reoccurrence. If new tests were found to predict not only the onset of the disease, but also its acute presence and reappearance, then the already overburdened medical system could benefit in the form of decreased hospitalizations and outpatient visits.

The American Heart Association (AHA) published a statement in 2009, which summarizes risk, its evaluation, prediction methods, and utility of novel markers in cardiovascular disease. ${ }^{4}$ This paper attempts to expand on the AHA position paper in order to further the understanding of what type of markers may be relevant clinically.

\section{Definition of and need for biomarkers}

In order to understand the role of biomarkers, it is useful to first define the term. In 2006, Vasan noted that the term 'biomarker' or 'biological marker' was first used in 1989 as a Medical Subject Heading to mean "measurable and quantifiable biological parameters which serve as indices for health- and physiology-related assessments such as disease risk, psychiatric disorders, environmental exposure and its effects, disease diagnosis, metabolic processes, substance abuse, pregnancy, cell line development, epidemiologic studies, etc." It was not until 12 years later in 2001 that the definition was standardized and further defined. At that time, the definition was narrowed to be "a characteristic that is objectively measured and evaluated as an indicator or normal biological processes." ${ }^{\circ}$ These can be measured in a bodily fluid (eg, blood, urine) or via medical imaging or testing.

One difficulty in establishing a novel, useful biomarkers is determining if it is causally related to the outcome of interest or if it is merely a confounder or proxy for an alternative factor, ie, risk marker or risk factor. The term 'risk factor' was first used in 1961 by Dr William Kannel of the Framingham Heart Study. ${ }^{7}$ It was intended to be used for "both causal and predictive factors." ${ }^{\prime 8}$ However, in current parlance, a risk marker is considered a risk factor if an intervention results in a change of risk. The most commonly cited example is that of hypertension as a risk factor for coronary artery disease because as blood pressure is decreased, studies have shown that coronary artery disease risk also decreases. ${ }^{8}$

While the definition of the term has changed over the years, so too have the statistics which are used to quantify the utility of each biomarker. The first statistic used is the receiver-operating characteristic (ROC). This curve plots the true versus false positives for a given test. The area under the curve (AUC) yields a c-statistic which assesses the AUC and estimates the probability that a given model assigns a higher risk to those who develop a disease than those who do not. ${ }^{9}$ For example, a c-statistic of 0.5 would suggest the assignment is due to chance, while a higher value has good capability of delineating cases from noncases. These two statistics were seen as insufficient because once several risk factors are added into a model, it is quite difficult to achieve a significant increase in the c-statistic. Pencina et al proposed another statistic to deal with this problem, the net 
reclassification index (NRI). ${ }^{10}$ This statistic assesses how individuals are moved from one risk classification to another based on the addition of further modeling variables. It can vary from -2 to +2 where positive indicates appropriate reclassification. ${ }^{10}$ Unfortunately, most new biomarkers have shown small NRIs in the $0.02-0.1$ range. ${ }^{9,11,12}$ Obviously, there is a need to discern in each case whether or not reclassifying patients is clinically significant and whether or not there is a benefit to doing so. Currently, there is no consensus regarding a clinically meaningful NRI; however, investigators should be encouraged to a priori develop categories that are clinically meaningful for their particular question.

There are three criteria that have been outlined for evaluating biomarkers: (1) ease of management, (2) addition of information, and (3) effect on management. Thus, it is important for any cardiovascular biomarker selected to not only be relatively simple to obtain across the population, but it must also add new information that other available tests do not. ${ }^{13}$ Finally, it must be something in response to which changes can be made to alter an outcome. It is this third criterion, which has precluded many biomarkers from reaching the clinical realm. ${ }^{14-16}$ For example, a population-based study in The Netherlands by Kavousi et al added B-type natriuretic peptide (BNP), von Willebrand factor antigen levels, fibrinogen, chronic kidney disease, leukocyte count, C-reactive protein (CRP), homocysteine, uric acid, coronary artery calcium scores, carotid intima-media thickness, peripheral arterial disease, and pulse-wave velocity to a risk-prediction model utilizing the traditional coronary disease risk factors described above. ${ }^{15}$ They found that coronary artery calcium was the only predictor that significantly improved risk predictions with a c-statistic of 0.05 and confidence interval (CI) of $0.02-0.06$ with a NRI of $19.3 \%$. They did not examine the cost-effectiveness of this test or take into account the radiation dosing this test would impart across a population. Ultimately, if it cannot be shown that patients live longer, better, or have fewer hospitalizations as a result of screening with a biomarker, it is unlikely to be deemed cost-effective and thus less likely to be covered by third-party payers.

For example, troponins were a successful biomarker because it allowed clinicians to separate those having an acute myocardial infarction from those who did not. They are also easy to measure and clearly gives information earlier than other available technologies such as a transthoracic echocardiogram where a wall motion abnormality might not be present despite an early, elevated troponin. They also clearly have an impact on management triaging a patient typically to hospital admission and early intervention. Recently, a small trial $(n=872)$ was published wherein patients with acute chest pain had high-sensitivity troponin $\mathrm{T}$ measurements done in a blinded fashion at baseline and within the first hour in the emergency department. Using this approach, $60 \%$ of patients could be ruled-out and $17 \%$ ruled-in with the remainder needing to be observed. The sensitivity and specificity were $100 \%$ and $97 \%$, respectively. ${ }^{17}$ If this data holds true in larger trials, this promising biomarker may obviate the need for some unnecessary admissions or observations thus freeing up health care resources for sicker patients.

Recently, Nadir et al published a study of 300 asymptomatic individuals in whom they performed echocardiography and stress testing to identify silent cardiac target end-organ damage including left ventricular hypertrophy, left atrial enlargement, systolic dysfunction, and ischemia (of note, the latter two only represented $12.6 \%$ of the outcomes). ${ }^{18}$ They found that BNP had an AUC of 0.78 for identifying the outcome of interest. They also found that high-sensitivity troponin $\mathrm{T}$ had an AUC of 0.7. The AUCs were lower for women than men. They suggest that perhaps the BNP could be used as a screening tool although, as this paper will describe, it is not enough to simply order a test if there is no additional opportunity to intervene to alter the natural history.

Thanks to the contribution of the Framingham Heart Study, a major epidemiologic study examining residents of Framingham, Massachusetts since 1948, there are now several, commonly accepted risk factors for cardiovascular disease including male sex, elevated low-density lipoproteins (LDL), smoking, hypertension, family history of premature coronary disease, and diabetes mellitus. From these factors, a risk score can be calculated; however, these risk factors do not account for all of the coronary disease risk. Large trials and meta-analyses have shown that approximately $90 \%$ of people who have an acute coronary syndrome have one of the major risk factors. ${ }^{19,20}$ In addition, $10 \%-15 \%$ of people who develop an acute coronary syndrome do not appear to have any identifiable risk factor and patients with traditional risk factors may not ever develop cardiovascular disease. Novel biomarkers seek to address this issue and will be the principal focus of the biomarker discussion in this paper.

\section{Examples of current biomarkers}

While the United States National Institutes of Health (NIH) began funding grants related to biomarkers in the 1980s, particularly within the realm of breast cancer, the number of NIH grants that contained the term 'biomarker' increased sharply in 2009. ${ }^{21}$ According to a database query by Ptolemy and Rifai, there was a fivefold increase in grants and a similar 
increase in funding from approximately $\$ 400$ million in 2008 to $\$ 2.1$ billion in $2009 .{ }^{21}$ While they note there are some methodologic limitations to this query, it clearly shows a recent increase in the topic as detailed solely by grant funding.

There are many biomarkers currently under study. For a detailed listing of some of the more common ones, see Table 1. Metalloproteinases, ${ }^{22} \mathrm{BNP}$, coronary artery

Table I Biomarkers for coronary artery disease ${ }^{62}$

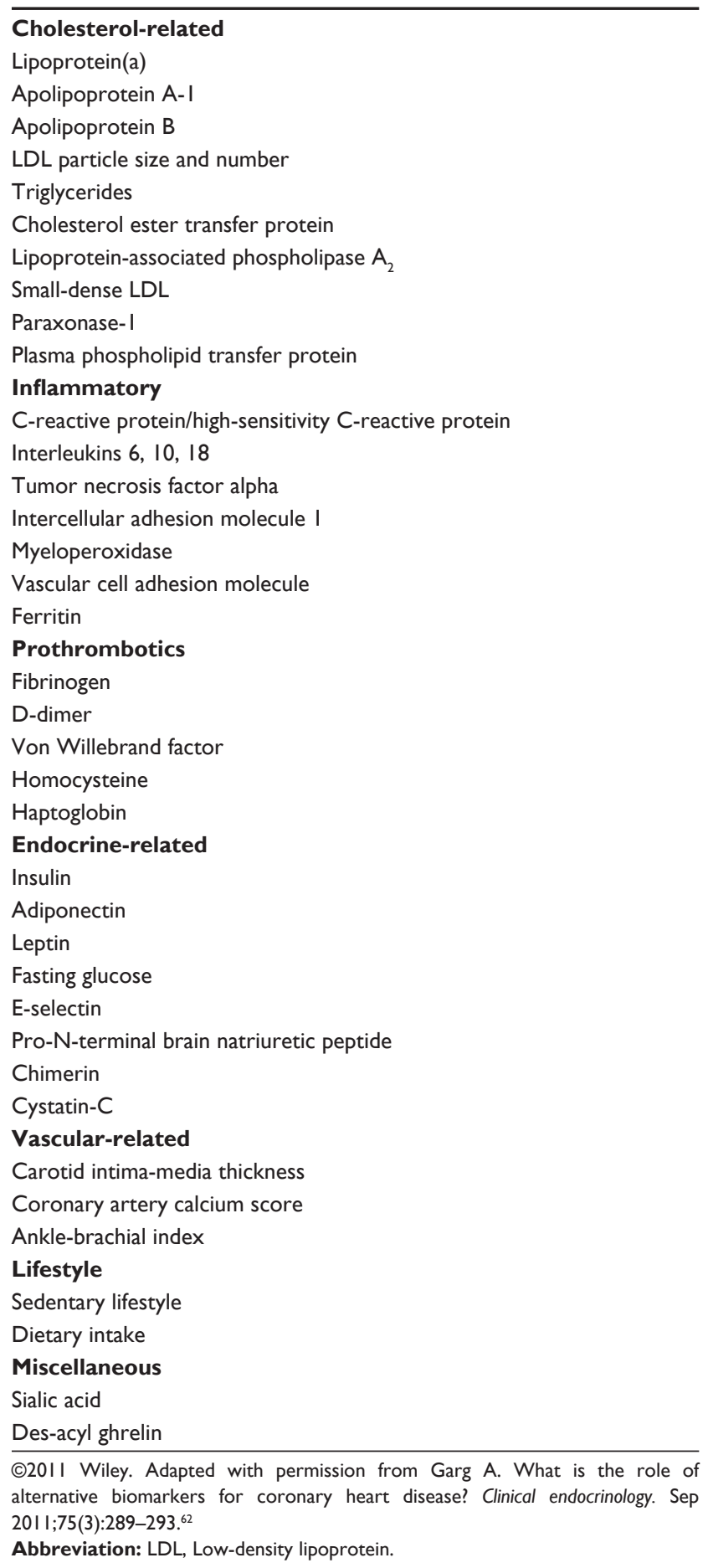

calcium, ${ }^{23}$ chimerin, ${ }^{24}$ adiponectin, ${ }^{25}$ alanine aminotransferase and gamma-glutamyltransferase, ${ }^{26}$ adiponectin and des-acyl ghrelin, ${ }^{27}$ plasma phospholipid-transfer protein, ${ }^{28}$ and sialic acid $^{29}$ have all been recently proposed as novel markers of cardiovascular disease or metabolic syndrome. There have been many reviews published in the past decade examining each of these in detail though most focus on the biochemical nature of the molecules and the laboratory undertakings for moving research forward. . $2,30,31^{2}$

There is also a disparity in the literature between primary and secondary prevention and whether or not there may be different biomarkers, which would be useful in each case. ${ }^{32,33}$ The Heart and Soul Study examined the additive predictive value of six biomarkers (N-terminal-pro-beta-natriuretic peptide [Nt-pro-BNP], cystatin $\mathrm{C}$, albuminuria, CRP, interleukin-6, and fibrinogen) in 979 patients who already had coronary artery disease. ${ }^{33}$ In this study, being in the highest vs the lowest three quartiles of Nt-proBNP was associated with a hazard ratio of 2.13 (95\% CI: 1.43-3.18). Being in the highest quartile of CRP vs the other three yielded a hazard ratio of 2 with a CI of 1.4-2.85. These two, along with albuminuria remained significant in multivariate analyses. Overall, the AUC in the ROC curve increased from 0.73 to 0.77 with the addition of these biomarkers in cases of secondary prevention. This suggests that there may be combinations of biomarkers that are useful and also that there is $23 \%$ of the AUC for which we have not yet accounted.

Table 2 describes 10 additional studies, which examined the addition of multiple biomarkers to accepted clinical risk factors for the determination of cardiovascular outcomes. This table shows that there is rarely more than a 3\%-4\% increase in the AUC and all areas centered around 65\%-80\%.

It is useful to examine the steps that need to be undertaken for future biomarkers by examining one of the more promising current ones. In this paper, CRP will be discussed as a candidate biomarker.

CRP was originally discovered by Tillett and Francis in 1930 and since it reacted with the C polysaccharide of Pneumococcus, it received its name. ${ }^{34}$ It is a member of the pentraxin family involved with acute immune responses that is formulated in the liver. ${ }^{35}$ It is thought to increase uptake of LDL by macrophages ${ }^{36}$ and to enhance local expression of multiple cell surface adhesion molecules ${ }^{37}$ and thus play a role in inflammation, and inflammation is known to mediate many atherosclerotic events.

Older assays used to measure CRP only detected levels $>10$ which signified an acute phase reactant in the setting of major illness. With the advent of high-sensitivity CRP (hsCRP) detection, researchers have been able to 


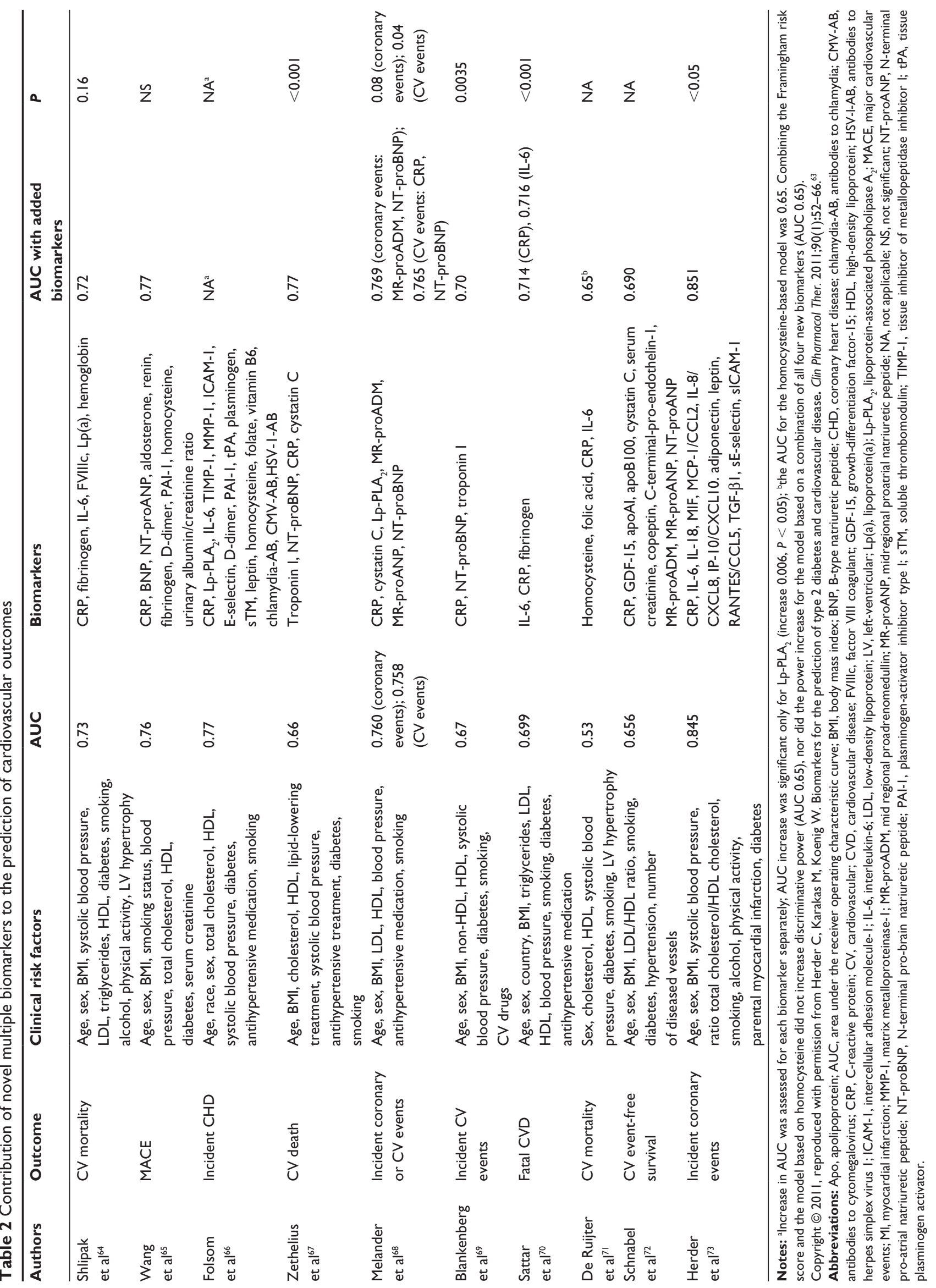


stratify by risk categories that are far below those that could be measured previously. In general, the classification strata have been that $>3 \mathrm{mg} / \mathrm{L}$ are high risk and $<1 \mathrm{mg} / \mathrm{L}$ are low risk while those between 1 and $3 \mathrm{mg} / \mathrm{L}$ are considered intermediate risk. ${ }^{38}$

There are several clinical trials in which CRP received much attention. In the Women's Health Study, a prospective case-control study of those in the Women's Health Initiative who developed heart disease, those with the highest CRP levels had a doubling of coronary heart disease. ${ }^{39}$ The Physicians' Health Study had similar data in that those with the highest levels of CRP had an adjusted relative risk of $2.9(P<0.001)$ for acute coronary syndrome compared to the lowest quartile. ${ }^{40}$ In addition, men who did not have a coronary syndrome at baseline, but who developed one over the ensuing 8 years were found to have significantly higher baseline CRP levels (1.51 vs $1.13 \mathrm{mg} / \mathrm{L} ; P=0.02){ }^{41}$

When the data from the entire Women's Health Initiative was analyzed by LDL and hsCRP levels at baseline, both were related to the development of subsequent cardiovascular events. Nearly half of the events occurred in patients with LDL levels below $130,{ }^{42}$ so it was purported that hsCRP might be a useful stratification tool.

Results from the Pravastatin or Atorvastatin Evaluation and Infection Therapy (PROVE-IT) ${ }^{43}$ are similar to those of the Reversal of Atherosclerosis with Aggressive Lipidlowering Therapy trial (REVERSAL), ${ }^{44}$ which is that there is atherosclerotic regression measured by intravascular ultrasound with both LDL and CRP lowering, therefore it has been posited that there may be a decrease in cardiovascular events if statin therapy is based on CRP values. ${ }^{38}$

The Air Force/Texas Coronary Atherosclerosis Prevention Study (AFCAPS/Tex-CAPS), another primary prevention trial, found that lovastatin lead to a $14 \%$ decrease in CRP levels $(P<0.001)$. If CRP was greater than the median level of $1.6 \mathrm{mg} / \mathrm{L}$, then the lovastatin lead to decreased cardiovascular event rates. If both CRP and the total cholesterol/ high-density lipoprotein ratio were lower than the median, then there was no effect of lovastatin. ${ }^{45}$

The Justification for the Use of Statins in Primary Prevention: An Intervention Trial Evaluating Rosuvastatin (JUPITER) was a primary prevention trial, which had hsCRP as one of its inclusion criteria. Nearly 18,000 people were enrolled with hsCRP $>2 \mathrm{mg} / \mathrm{L}$. The trial was stopped prematurely by the Data Safety Monitoring Board. The results showed that statin use significantly lowered the rate of first major cardiovascular event among those with baseline LDL levels less than 130 with a hazard ratio of 0.56 (95\% CI: $0.46-0.69$ ) and lowered CRP by 37\% when compared with placebo. ${ }^{46}$ The trial did not evaluate the benefits of statin therapy in those with hsCRP $<2$ as they were not included in the trial. It also did not evaluate hsCRP as an independent predictor of major cardiovascular events.

Among those with established coronary artery disease, levels of hsCRP have been shown to be correlated with recurrent events. ${ }^{47}$ In addition, as Tsimikas et al noted in $2006,{ }^{48}$ elevated levels of hsCRP have also been shown to predict vascular risk in patients undergoing elective percutaneous coronary interventions and coronary artery bypass graft surgery. ${ }^{49}$ For those with known cardiovascular disease, the Cholesterol and Recurrent Events Trial (CARE), a doubling of recurrent events for those in the highest quintile of CRP was noted. ${ }^{50}$ Also in patients with acute coronary syndromes, high CRP levels portend a poorer prognosis. ${ }^{51}$

Despite the abundance of clinical data suggesting that CRP may be a risk factor in the pathway to atherosclerotic cardiovascular disease, the basic science analyses of CRP and heart disease have thus far been less favorable. ${ }^{52,53} \mathrm{~A}$ recently published genetics study of four CRP gene polymorphisms concluded that there was no increased risk of heart disease with additional copies of these alleles, thus concluding that CRP may not be a risk factor in heart disease. ${ }^{52}$

CRP has not been shown to change the c-statistic of the ROC curve ${ }^{54}$ and it has also not led to a substantial NRI in most populations. ${ }^{9}$ However, for those who are in an intermediate-risk category, a recent meta-analysis concluded there is strong evidence that CRP has predictive value for cardiovascular events independent of other risk factors and that moderate evidence suggests that may improve risk stratification for those at intermediate risk. ${ }^{55}$ It has already been added to the European Society of Cardiology's guidelines for risk stratification of patients with acute coronary syndrome. ${ }^{56}$ In the United States, the most recent American College of Cardiology/AHA guidelines for the assessment of asymptomatic adults listed measuring hsCRP as a Class IIa indication for men and women with LDL $<130$ in order to decide whether or not to use a statin. A Class IIb indication was given to measuring hsCRP for risk stratification in women over 60 years and men over 50 years of age.

In addition, a recent systematic review by Micha et al examined cardiovascular disease risk and methotrexate use. ${ }^{57}$ The hypothesis was that a disease-modifying antirheumatic drug used for inflammatory disorders could also lead to a lower rate of cardiovascular disease mediated 
via the inflammatory pathway. Their conclusion was that methotrexate use was associated with a $21 \%$ lower risk of cardiovascular disease and $18 \%$ lower risk of myocardial infarction. ${ }^{57}$ This lends promise to the notion that identifying markers of inflammation may allow interventions to decrease overall cardiovascular risk.

\section{Approval process for utilizing biomarkers in clinical practice}

The Food and Drug Administration (FDA) funded a study undertaken by the Institute of Medicine (IOM) to "(1) evaluate risk biomarkers and surrogate endpoints in chronic diseases, using cancer and cardiovascular disease as prototypes; (2) use existing prototypes to develop a framework that can be employed by various entities including the National Institutes of Health, Congress, and the FDA to assess the utility of biomarkers as surrogates in particular disease processes". ${ }^{58,59}$ The findings from this expert panel helped lay the groundwork for what would constitute a useful biomarker and surrogate endpoint via framework conceptualization, statistical references, and case studies.

\section{Conclusion}

In summary, cardiovascular disease is a growing problem in the United States and in most developed nations worldwide. ${ }^{60}$ Traditional risk factors do not account for the entirety of risk and there are many people who have events who do not fit the traditional definition of "high risk". To that end, new biomarkers must be developed in order to find ways of identifying those individuals at risk in an attempt to alter their course either primarily or secondarily. CRP was used as an example to show a molecule that has undergone significant study, but for which ways to intervene for a given individual are not yet known. Further study in this realm will hopefully elucidate the role of hsCRP and other markers like it.

The FDA has made great strides towards defining and delineating ways in which biomarkers can be approved for use. This will hopefully also change the way in which policymakers use the scientific information to inform policy.

Perhaps with these strides we will move closer to the Hippocratic teaching that "it is more important to know what sort of person has a disease than to know what sort of disease a person has" and that in doing so, the health of our population will continue to improve.

\section{Disclosure}

The authors report no conflicts of interest in this work.

\section{References}

1. Mensah GA, Brown DW. An overview of cardiovascular disease burden in the United States. Health Aff (Millwood). 2007;26(1):38-48.

2. Lloyd-Jones DM, Larson MG, Beiser A, Levy D. Lifetime risk of developing coronary heart disease. Lancet. 1999;353(9147):89-92.

3. National Heart L, and Blood Institute. FY 2011 Fact Book. 2011. Available from: http://www.nhlbi.nih.gov/about/factbook/ FactBook2011.pdf. Accessed August 24, 2012.

4. Hlatky MA, Greenland P, Arnett DK, et al. Criteria for evaluation of novel markers of cardiovascular risk: a scientific statement from the American Heart Association. Circulation. 2009;119(17):2408-2416.

5. Vasan RS. Biomarkers of cardiovascular disease: molecular basis and practical considerations. Circulation. 2006;113(19):2335-2362.

6. Biomarkers and surrogate endpoints: preferred definitions and conceptual framework. Clin Pharmacol Ther. 2001;69(3):89-95.

7. Kannel WB, Dawber TR, Kagan A, Revotskie N, Stokes J 3rd. Factors of risk in the development of coronary heart disease - six year follow-up experience. The Framingham Study. Ann Intern Med. 1961;55:33-50.

8. Stampfer MJ, Ridker PM, Dzau VJ. Risk factor criteria. Circulation. 2004;109(25 Suppl 1):IV3-IV5.

9. Wilkins JT, Lloyd-Jones DM. Biomarkers for coronary heart disease clinical risk prediction: a critical appraisal. Counterpoint. Prev Cardiol. 2010;13(4):160-165.

10. Pencina MJ, D'Agostino RB Sr, D'Agostino RB Jr, Vasan RS. Evaluating the added predictive ability of a new marker: from area under the ROC curve to reclassification and beyond. Stat Med. 2008;27(2):157-172; discussion 207-212.

11. Shah T, Casas JP, Cooper JA, et al. Critical appraisal of CRP measurement for the prediction of coronary heart disease events: new data and systematic review of 31 prospective cohorts. Int J Epidemiol. 2009;38(1):217-231.

12. Greenland P, Alpert JS, Beller GA, et al. 2010 ACCF/AHA guideline for assessment of cardiovascular risk in asymptomatic adults: executive summary: a report of the American College of Cardiology Foundation/American Heart Association Task Force on Practice Guidelines. Circulation. 2010;122(25):2748-2764.

13. Wilson PW. Challenges to improve coronary heart disease risk assessment. JAMA. 2009;302(21):2369-2370.

14. Wang TJ, Gona P, Larson MG, et al. Multiple biomarkers for the prediction of first major cardiovascular events and death. $N$ Engl $J$ Med. 2006;355(25):2631-2639.

15. Kavousi M, Elias-Smale S, Rutten JH, et al. Evaluation of newer risk markers for coronary heart disease risk classification: a cohort study. Ann Intern Med. 2012;156(6):438-444.

16. Folsom AR, Chambless LE, Ballantyne CM, et al. An assessment of incremental coronary risk prediction using $\mathrm{C}$-reactive protein and other novel risk markers: the atherosclerosis risk in communities study. Arch Intern Med. 2006;166(13):1368-1373.

17. Reichlin T, Schindler C, Drexler B, et al. One-hour rule-out and rule-in of acute myocardial infarction using high-sensitivity cardiac troponin T. Arch Intern Med. 2012;172(16):1211-1218.

18. Nadir MA, Rekhraj S, Wei L, et al. Improving the primary prevention of cardiovascular events by using biomarkers to identify individuals with silent heart disease. J Am Coll Cardiol. 2012;60(11):960-968.

19. Greenland P, Knoll MD, Stamler J, et al. Major risk factors as antecedents of fatal and nonfatal coronary heart disease events. JAMA. 2003;290(7):891-897.

20. Khot UN, Khot MB, Bajzer CT, et al. Prevalence of conventional risk factors in patients with coronary heart disease. JAMA. 2003;290(7): 898-904.

21. Ptolemy AS, Rifai N. What is a biomarker? Research investments and lack of clinical integration necessitate a review of biomarker terminology and validation schema. Scand J Clin Lab Invest Suppl. 2010;242:6-14. 
22. Palazzuoli A, Iovine F, Gallotta M, Nuti R. Emerging cardiac markers in coronary disease: role of brain natriuretic peptide and other biomarkers. Minerva Cardioangiol. 2007;55(4):491-496.

23. Rana JS, Gransar H, Wong ND, et al. Comparative value of coronary artery calcium and multiple blood biomarkers for prognostication of cardiovascular events. Am J Cardiol. 2012;109(10):1449-1453.

24. Dong B, Ji W, Zhang Y. Elevated serum chemerin levels are associated with the presence of coronary artery disease in patients with metabolic syndrome. Intern Med. 2011;50(10):1093-1097.

25. Wang JH, Lee CJ, Lee CC, Chen YC, Lee RP, Hsu BG. Fasting adiponectin is inversely correlated with metabolic syndrome in patients with coronary artery disease. Intern Med. 2010;49(8):739-747.

26. Saely $\mathrm{CH}$, Vonbank A, Rein $\mathrm{P}$, et al. Alanine aminotransferase and gamma-glutamyl transferase are associated with the metabolic syndrome but not with angiographically determined coronary atherosclerosis. Clin Chim Acta. 2008;397(1-2):82-86.

27. Yano $\mathrm{Y}$, Toshinai $\mathrm{K}$, Inokuchi $\mathrm{T}$, et al. Plasma des-acyl ghrelin, but not plasma HMW adiponectin, is a useful cardiometabolic marker for predicting atherosclerosis in elderly hypertensive patients. Atherosclerosis. 2009;204(2):590-594.

28. Tzotzas T, Desrumaux C, Lagrost L. Plasma phospholipid transfer protein (PLTP): review of an emerging cardiometabolic risk factor. Obesity Rev. 2009;10(4):403-411.

29. Gopaul KP, Crook MA. Sialic acid: a novel marker of cardiovascular disease? Clin Biochem. 2006;39(7):667-681.

30. Marian AJ, Nambi V. Biomarkers of cardiac disease. Exp Rev Mol Diagn. 2004;4(6):805-820.

31. Reynolds RM, Ilyas B, Price JF, et al. Circulating plasma cortisol concentrations are not associated with coronary artery disease or peripheral vascular disease. QJM. 2009;102(7):469-475.

32. Koenig W. Update on integrated biomarkers for assessment of longterm risk of cardiovascular complications in initially healthy subjects and patients with manifest atherosclerosis. Ann Med. 2009;41(5): 332-343.

33. Shlipak MG, Ix JH, Bibbins-Domingo K, Lin F, Whooley MA. Biomarkers to predict recurrent cardiovascular disease: the Heart and Soul Study. Am J Med. 2008;121(1):50-57.

34. Tillett WS, Francis T. Serological reactions in pneumonia with a non-protein somatic fraction of Pneumococcus. J Exper Med. 1930;52(4):561-571.

35. Bassuk SS, Rifai N, Ridker PM. High-sensitivity C-reactive protein: clinical importance. Curr Probl Cardiol. 2004;29(8):439-493.

36. Zwaka TP, Hombach V, Torzewski J. C-reactive protein-mediated low density lipoprotein uptake by macrophages: implications for atherosclerosis. Circulation. 2001;103(9):1194-1197.

37. Pasceri V, Willerson JT, Yeh ET. Direct proinflammatory effect of C-reactive protein on human endothelial cells. Circulation. 2000; 102(18):2165-2168

38. Jaffe AS, Babuin L, Apple FS. Biomarkers in acute cardiac disease: the present and the future. J Am Coll Cardiol. 2006;48(1):1-11.

39. Pradhan AD, Manson JE, Rossouw JE, et al. Inflammatory biomarkers, hormone replacement therapy, and incident coronary heart disease: prospective analysis from the Women's Health Initiative observational study. JAMA. 2002;288(8):980-987.

40. Ridker PM, Cushman M, Stampfer MJ, Tracy RP, Hennekens CH. Inflammation, aspirin, and the risk of cardiovascular disease in apparently healthy men. N Engl J Med. 1997;336(14):973-979.

41. Cannon CP, Steinberg BA. Evidence-Based Cardiology. Philadelphia, PA: Wolters Kluwer; 2011.

42. Ridker PM, Rifai N, Rose L, Buring JE, Cook NR. Comparison of C-reactive protein and low-density lipoprotein cholesterol levels in the prediction of first cardiovascular events. $N$ Engl $J$ Med. 2002;347(20):1557-1565.

43. Dupuis J, Tardif JC, Rouleau JL, et al. Cannon CP. Intensity of lipid lowering with statin and brachial artery vascular endothelium reactivity after acute coronary syndromes. Am J Cardiol. 2005 Nov 1; 96(9): 1207-1213.
44. Nissen SE, Tuzcu EM, Schoenhagen P, et al. Effect of intensive compared with moderate lipid-lowering therapy on progression of coronary atherosclerosis: a randomized controlled trial. JAMA. 2004; 291(9): 1071-1080.

45. Ridker PM, Rifai N, Clearfield M, et al. Measurement of C-reactive protein for the targeting of statin therapy in the primary prevention of acute coronary events. $N$ Engl J Med. 2001;344(26):1959-1965.

46. Ridker PM, Danielson E, Fonseca FA, et al. Rosuvastatin to prevent vascular events in men and women with elevated C-reactive protein. N Engl J Med. 2008;359(21):2195-2207.

47. Haverkate F, Thompson SG, Pyke SD, Gallimore JR, Pepys MB. Production of C-reactive protein and risk of coronary events in stable and unstable angina. European Concerted Action on Thrombosis and Disabilities Angina Pectoris Study Group. Lancet. 1997;349(9050): 462-466.

48. Tsimikas S, Willerson JT, Ridker PM. C-reactive protein and other emerging blood biomarkers to optimize risk stratification of vulnerable patients. J Am Coll Cardiol. 2006;47(Suppl 8):C19-C31.

49. Milazzo D, Biasucci LM, Luciani N, et al. Elevated levels of C-reactive protein before coronary artery bypass grafting predict recurrence of ischemic events. Am J Cardiol. 1999;84(4):459-461, A459.

50. Ridker PM, Rifai N, Pfeffer MA, et al. Inflammation, pravastatin, and the risk of coronary events after myocardial infarction in patients with average cholesterol levels. Cholesterol and Recurrent Events (CARE) Investigators. Circulation. 1998;98(9):839-844.

51. Mueller C, Buettner HJ, Hodgson JM, et al. Inflammation and long-term mortality after non-ST elevation acute coronary syndrome treated with a very early invasive strategy in 1042 consecutive patients. Circulation. 2002;105(12):1412-1415.

52. Wensley F, Gao P, Burgess S, et al. Association between C-reactive protein and coronary heart disease: mendelian randomisation analysis based on individual participant data. BMJ. 2011;342:d548.

53. Elliott P, Chambers JC, Zhang W, et al. Genetic loci associated with C-reactive protein levels and risk of coronary heart disease. JAMA. 2009;302(1):37-48.

54. Cook NR, Buring JE, Ridker PM. The effect of including C-reactive protein in cardiovascular risk prediction models for women. Ann Intern Med. 2006;145(1):21-29.

55. Buckley DI, Fu R, Freeman M, Rogers K, Helfand M. C-reactive protein as a risk factor for coronary heart disease: a systematic review and meta-analyses for the US Preventive Services Task Force. Ann Intern Med. 2009;151(7):483-495.

56. Konstantino Y, Wolk R, Terra SG, Nguyen TT, Fryburg DA. Non-traditional biomarkers of atherosclerosis in stable and unstable coronary artery disease, do they differ? Acute Cardiac Care. 2007;9(4):197-206.

57. Micha R, Imamura F, Wyler von Ballmoos M, et al. Systematic review and meta-analysis of methotrexate use and risk of cardiovascular disease. Am J Cardiol. 2011;108(9):1362-1370.

58. Albert MA. Biomarkers and heart disease. J Clin Sleep Med. 2011;7(Supp1 5):S9-S11.

59. Disease CoQoBaSEiC, Medicine Io. Evaluation of Biomarkers and Surrogate Endpoints in Chronic Disease. Washington, DC: National Academies Press; 2010.

60. Kim HC. Clinical utility of novel biomarkers in the prediction of coronary heart disease. Korean Circ J. 2012;42(4):223-228.

61. National Heart Lung, and Blood Institute. FY 2011 Fact Book. 2011. Available from: http://www.nhlbi.nih.gov/about/factbook/ FactBook2011.pdf. Accessed August 24, 2012.

62. Garg A. What is the role of alternative biomarkers for coronary heart disease? Clinical endocrinology. Sep 2011;75(3):289-293.

63. Herder C, Karakas M, Koenig W. Biomarkers for the prediction of type 2 diabetes and cardiovascular disease. Clin Pharmacol Ther. 2011;90(1):52-66.

64. Shlipak MG, Fried LF, Cushman M, Manolio TA, Peterson D, StehmanBreen C, Bleyer A, Newman A, Siscovick D, Psaty B. Cardiovascular mortality risk in chronic kidney disease: comparison of traditional and novel risk factors. JAMA. 2005; 293(14):1737-1745. 
65. Wang TJ, Gona P, Larson MG, et al. Multiple biomarkers for the prediction of first major cardiovascular events and death. $N$ Engl J Med. 2006;355(25):2631-2639.

66. Folsom AR, Chambless LE, Ballantyne CM, et al. An assessment of incremental coronary risk prediction using $\mathrm{C}$-reactive protein and other novel risk markers: the atherosclerosis risk in communities study. Arch Intern Med. 2006;166(13):1368-1373.

67. Zethelius B, Berglund L, Sundström J, et al. Use of multiple biomarkers to improve the prediction of death from cardiovascular causes. $N$ Engl J Med. 2008;358(20):2107-2116.

68. Melander O, Newton-Cheh C, Almgren P, et al. Novel and conventional biomarkers for prediction of incident cardiovascular events in the community. JAMA. 2009;302(1):49-57.

69. Blankenberg S, Zeller T, Saarela O, et al. MORGAM Project. Contribution of 30 biomarkers to 10 -year cardiovascular risk estimation in 2 population cohorts: the MONICA, risk, genetics, archiving, and monograph (MORGAM) biomarker project. Circulation. 2010; 121(22):2388-2397.
70. Sattar N, Murray HM, Welsh P, et al. Prospective Study of Pravastatin in the Elderly at Risk (PROSPER) Study Group. Are markers of inflammation more strongly associated with risk for fatal than for nonfatal vascular events? PLoS Med. 2009;23;6(6):e1000099.

71. de Ruijter W, Westendorp RG, Assendelft WJ, et al. Use of Framingham risk score and new biomarkers to predict cardiovascular mortality in older people: population based observational cohort study. $B M J$. 2009;338:a3083.73.

72. Schnabel RB, Schulz A, Messow CM, et al. Multiple marker approach to risk stratification in patients with stable coronary artery disease. Eur Heart J. 2010;31(24):3024-3031.

73. Herder C, Baumert J, Zierer A, et al. Immunological and cardiometabolic risk factors in the prediction of type 2 diabetes and coronary events: MONICA/KORA Augsburg case-cohort study. PLoS One. 2011;6(6):e19852.
Vascular Health and Risk Management

\section{Publish your work in this journal}

Vascular Health and Risk Management is an international, peerreviewed journal of therapeutics and risk management, focusing on concise rapid reporting of clinical studies on the processes involved in the maintenance of vascular health; the monitoring, prevention and treatment of vascular disease and its sequelae; and the involvement of

\section{Dovepress}

metabolic disorders, particularly diabetes. This journal is indexed on PubMed Central and MedLine. The manuscript management system is completely online and includes a very quick and fair peer-review system, which is all easy to use. Visit http://www.dovepress.com/ testimonials.php to read real quotes from published authors. 